\title{
BILATERAL VASO-OCCLUSIVE RETINOPATHY AS AN INITIAL MANIFESTATION OF SYSTEMIC LUPUS ERYTHEMATOSUS ASSOCIATED WITH THE ANTIPHOSPHOLIPID SYNDROME
}

Luana Gerheim Machado ${ }^{1, \star}$, Juliana Ferreira Bezerra de Azevedo ${ }^{1}$, Ellen Pinheiro Tenório de Albuquerque ${ }^{1}$, Marcos Roberto de Carvalho ${ }^{1}$, Herval de Lacerda Bonfante ${ }^{1}$

1.Hospital Maternidade Therezinha de Jesus, Juiz de Fora (MG), Brazil.

*Corresponding author: luanagerheim@yahoo.com.br

\section{BACKGROUND}

Systemic lupus erythematosus (SLE) is an autoimmune multisystemic disease characterized by multiple organ involvement, including the eye. Severe vaso-occlusive retinopathy is a rare, sight-threatening manifestation of the disease, which is more common in patients with associated antiphospholipid syndrome. The objective of the study is to report a rare case of a patient with severe bilateral vaso-occlusive retinopathy as an initial manifestation of SLE associated with the antiphospholipid syndrome.

\section{CASE REPORT}

In January 2020, a 37-year-old male patient was admitted to the hospital due to a 3-week history of progressive bilateral visual loss. The symptom started suddenly in the left eye and subsequently affected the right eye. There were no preceding episodes of transient blurring of vision. There was no ocular redness, discharge, pain or periorbital swelling. He also complained of asthenia, nausea, hyporexia and macroscopic hematuria for a week. Ophthalmological examination revealed intraretinal hemorrhages, severe macular ischemia and widespread occlusion of small retinal vessels of both eyes. Laboratory tests showed microcytic hypochromic anemia $(\mathrm{Hb}: 8.9 \mathrm{~g} / \mathrm{dL})$, thrombocytopenia $\left(88,970 / \mathrm{mm}^{3}\right)$, a raised ESR $(99 \mathrm{~mm} / \mathrm{h})$ and an elevated serum creatinine of $1.6 \mathrm{mg} / \mathrm{dL}$. Urinalysis revealed 2+ proteinuria, 3+ blood and no bacterial growth in urine culture. Immunoserology demonstrated positive tests for antinuclear antibody (ANA), anti-SS-A, anti-SS-B and elevated titers of anti-double stranded DNA (anti-ds-DNA) antibody. Complement levels were normal and rheumatoid factor was negative. The antiphospholipid antibody (aPL) screening test

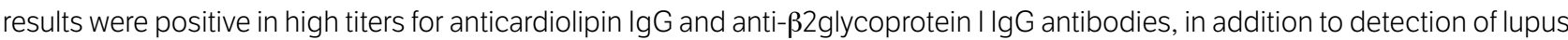
anticoagulant. In the setting of a severe vaso-occlusive retinopathy secondary to SLE associated with antiphospholipid syndrome, the patient was promptly treated with intravenous (IV) methylprednisolone $1 \mathrm{~g}$ daily $\times 3$ days followed by systemic prednisone at $1 \mathrm{mg} / \mathrm{kg}$ daily and hydroxychloroquine $400 \mathrm{mg} /$ day. Besides, full anticoagulation therapy with enoxaparin bridged to warfarin was simultaneously started. There was a good clinical evolution of the systemic condition, but the patient did not recover from bilateral visual loss, especially in the left eye. After hospital discharge, the patient underwent specific ophthalmic treatment with pan-retinal photocoagulation for both eyes, however, this did not prevent deterioration in his visual acuity.

\section{CONCLUSION}

This case highlights the importance of bilateral vaso-occlusive retinopathy as an initial presentation of SLE associated with the antiphospholipid syndrome. Therefore, it is important for physicians to recognize this condition to start aggressive treatment early, in order to avoid severe visual loss. 